\title{
Mechanical Properties of a Vacuum-Sintered Apatite Body for Use as Artificial Bone
}

\author{
Kenichi Tamura \\ College of Engineering, Nihon University, Koriyama, Japan \\ Email: tamura@mech.ce.nihon-u.ac.jp \\ Academic Editor: Jinghua Duan, University of Washington, USA \\ Received 10 October 2014; revised 23 October 2014; accepted 1 November 2014 \\ Copyright (C) 2015 by author and Scientific Research Publishing Inc. \\ This work is licensed under the Creative Commons Attribution International License (CC BY). \\ http://creativecommons.org/licenses/by/4.0/

(c) (i) Open Access

\section{Abstract}

Regenerative artificial bone material and bone parts were fabricated using vacuum-sintered bodies of a "titanium medical apatite (TMA $®$ )" that is formed by chemically connecting Ti oxide molecules to the reactive $\left[\mathrm{Ca}_{10}\left(\mathrm{PO}_{4}\right)_{6}\right]$ group of hydroxyapatite (HAp). Sintering at temperatures of $1273-1773 \mathrm{~K}$ caused this TMA sintered bodies to recrystallize and form a varying mix of $\alpha$-TCP (tricalcium phosphate), $\beta$-TCP and Perovskite-CaTiO ${ }_{3}$ phases. The Perovskite crystals proved to be quite stable and hard, forming a uniform distribution of similarly sized fibers in all directions under vacuum sintering, but an irregular distribution and size when sintered in the presence of oxygen. Complete recrystallization was achieved by vacuum sintering at temperatures in excess of $1473 \mathrm{~K}$. In particular, TMA vacuum-sintered bodies at $1573 \mathrm{~K}$ are given the maximum value; a Vickers hardness of 400, a bending strength of $43 \mathrm{MPa}$, a compressive strength of $270 \mathrm{MPa}$ and a density of approximately $2300 \mathrm{~kg} / \mathrm{m}^{3}$ was achieved that closely corresponds to that of compact bone or a tooth. As these TMA bodies could also be cut into various forms, they are considered a promising biomaterial for use as artificial bone in the regeneration of natural bone, or to provide reinforcement of bone junctions in dental and orthopedic surgery.

\section{Keywords}

Titanium Medical Apatite (TMA), Vacuum Sintering, Vickers Hardness, Bending Strength, Compressive Strength, Crystal Morphology, Regenerative Artificial Bone

\section{Introduction}

Artificial joints and roots are typically made from alloys such as stainless steel, titanium or Co-Cr [1]-[4], but if their adhesion to bone is poor then it can lead to loosening of the implant or bone breakage. If this does occur, or 
if there is an intense allergic reaction to the metal implant, then re-operation is usually required [5]. In a bid to avoid this, metal implants have been recently developed with a surface coating of hydroxyapatite (HAp) or tricalcium phosphate (TCP), both of which are constituents of natural bone and therefore help ensure excellent biocompatibility with human bone and teeth [6]-[8].

Granular forms, round bars, and boards of compressed HAp powders have also been developed that can be sintered in atmosphere at $1073-1273 \mathrm{~K}$ to produce artificial bone grafts, which are then inserted in the space between the bone and an implant [9]. The inherent porosity of these bone grafts means that they lack the strength needed to support the weight of a human, but they do have an excellent ability to create mature myeloid tissue. Given this, we have previously manufactured a vacuum-sintered body from a novel "titanium medical apatite (TMA $\left.{ }^{\circledR}\right)$ " for use as a bone replacement in humans. Figure 1 [10] shows examples of just some of the biomaterial parts that can be produced from a TMA body vacuum sintered at $1573 \mathrm{~K}$ by simply cutting with a 3D-modeling machine or a lathe. In this way the surface roughness is kept quite smooth at $\mathrm{Ra}=0.24 \mu \mathrm{m}$, while still maintaining a density comparable to that of compact human bone and teeth $\left(2300 \mathrm{~kg} / \mathrm{m}^{3}\right)$ [11].

The structure of TMA bodies vacuum sintered at $1073 \mathrm{~K}$ has been found to be a mix of the original starting materials and crystalline phases such as $\beta$-TCP [Whitlockite- $\left.\mathrm{Ca}_{3}\left(\mathrm{PO}_{4}\right)_{2}\right]$ and Perovskite-CaTiO${ }_{3}$; however, increasing the sintering temperature to 1473 - $1773 \mathrm{~K}$ causes a complete recrystallization to $\beta$-TCP, $\alpha$-TCP and Perovskite [10]. The implantation of this vacuum-sintered TMA material inside the bodies of mice at Panapharm Laboratories, Ltd. (Kumamoto, Japan), and subsequent histocompatibility tests, identified it as being non-toxic. This was further confirmed by inserting TMA bodies sintered at $1573 \mathrm{~K}$ and Ti metal (99.9\% pure) into the mandibles of rabbits, with both materials being equally well tolerated by the surrounding tissue, and no evidence found of any adverse tissue reaction. The outer surface of both materials was also found to be covered by new bone tissue, but the Ti metal implant was also coated with a layer of Ti oxide [12] [13].

In result, an international patent (W02005-058754) [14], "Sintered body of titanium compound,” i.e., "TMA sintered body", has been applied for. We have also taken out patents in United States (US7803194B2), Australia (AU2004299390B2), Japan (JP5111761), Canada (CA2549866), Korea (10-1132991) and China (CN100534897C). And, Immuno-Science Co., Ltd. (Sapporo, Japan) has acquired a registered trademark (No.4955755 in Japan) of "TMA".

Given the promising performance of vacuum-sintered TMA bodies with regards to their biocompatibility, this paper investigates the effect of varying the sintering temperature on their hardness, bending strength and compressive strength so as to assess their suitability for use as artificial bone and tooth parts.

\section{Experimental Method}

\subsection{Materials}

The TMA powder used in this study was manufactured by the Taihei Chemical Industrial Co., Ltd. (Osaka, Japan), and had a mean particle diameter of $4.3 \mu \mathrm{m}$. This was kneaded with distilled water to form solid cylinders (16 mm in diameter $\times 20 \mathrm{~mm}$ in length), which were then compacted by compression molding at $10 \mathrm{MPa}$ in a stainless-steel vessel. The resulting compacts were dried at $383 \mathrm{~K}$ for 12 hours, and then sintered under vacuum (about $10^{-3} \mathrm{~Pa}$ ) or in atmosphere using a resistance heating furnace (Suga Co., Ltd., Hakodate, Japan, AL048). Details of the sintering conditions are provided in Table 1.

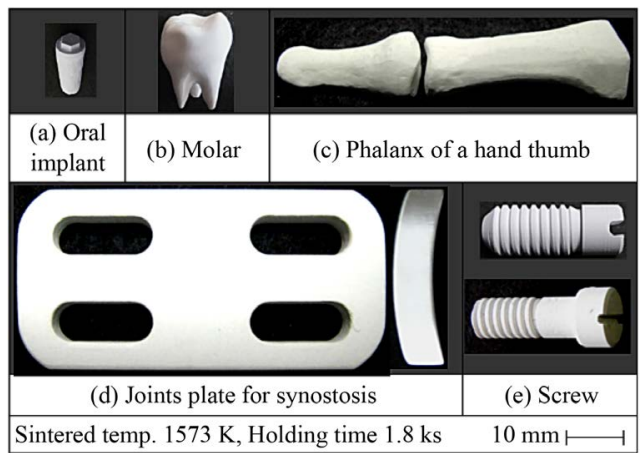

Figure 1. Biomaterial parts cut from vacuum-sintered TMA bodies using a 3D-modeling machine or lathe. 
Table 1. Sintering conditions used.

\begin{tabular}{cc}
\hline Sintering temp. & $1273-1773 \mathrm{~K}$ \\
Holding time & $1.8 \mathrm{ks}$ \\
& $0.4 \mathrm{~K} / \mathrm{s}(-1073 \mathrm{~K})$ \\
Heading rate & $0.4 \mathrm{~K} / \mathrm{s}(1073-1173 \mathrm{~K})$ \\
& $0.05 \mathrm{~K} / \mathrm{s}(1173-1773 \mathrm{~K})$ \\
Cooling rate & $0.05 \mathrm{~K} / \mathrm{s}(1773-1273 \mathrm{~K})$ \\
& $0.1 \mathrm{~K} / \mathrm{s}(-1273 \mathrm{~K})$ \\
Compressive stress & $0 \mathrm{MPa}$ \\
Atomsphere & Vacuum (8 mPa), Air \\
\hline
\end{tabular}

\subsection{Vickers Hardness Tests}

Vickers hardness tests were carried out using a load force $F$ of $4.9 \mathrm{~N}$ and a holding time of $30 \mathrm{~s}$ with a HM-102 hardness testing machine (Akashi Co., Zama, Japan). For this, sintered TMA bodies were machined by a lathe to solid cylinders of approximately $11 \mathrm{~mm}$ in diameter and $15 \mathrm{~mm}$ in length, one end of which was polished with \#1500 waterproof abrasive paper to provide a suitable surface for measurement. The Vickers hardness was determined from an average of three specimens sintered at the same temperature using the formula:

$$
H V=0.18191 \frac{F}{a^{2}}
$$

where $a$ is the average value of the diagonal length of the indentation.

\subsection{Bending Tests}

Four-point bending tests were carried out at a load speed of $0.25 \mathrm{~N} / \mathrm{s}$ in water using a laboratory-made bending machine, in which the distance between fulcrums was $\mathrm{L}=20 \mathrm{~mm}$. Bending specimens were produced by a lathe to dimension of $6 \mathrm{~mm}$ diameter $\times 30 \mathrm{~mm}$ in length ( parallel part $4 \mathrm{~mm}$ in diameter $\times 8 \mathrm{~mm}$ in length). The bending stress $\sigma_{b}$ was calculated as:

$$
\sigma_{b}=\frac{M}{Z}=\frac{\frac{1}{2} W L}{\frac{\pi d^{3}}{32}}=\frac{16 W L}{\pi d^{3}}
$$

where $M$ is the bending moment, $Z$ the section modulus, $W$ the load, $L$ the distance between fulcrums, and $d$ the parallel partdiameter.

\subsection{Compression Tests}

Compression tests were carried out at a load speed of $98 \mathrm{~N} / \mathrm{s}$ using a SUVT-type material testing machine (maximum load $100 \mathrm{kN}$ ) manufactured by the Sansei Industrial Co., Ltd. (Tokyo, Japan). The specimens used were solid cylinders (11 $\mathrm{mm}$ in diameter $\times 15 \mathrm{~mm}$ in length) produced by a lathe and polished on both ends by \#1500 waterproof abrasive paper.

\subsection{SEM Study}

The fracture surfaces produced by these compression tests were observed using a JSM 6500F field emission scanning electron microscope (FE-SEM) manufactured by JEOL (Tokyo, Japan) at an electron voltage of $10 \mathrm{kV}$.

\subsection{X-Ray Diffraction Study}

The TMA sintered bodies were ground using an agate mortar to prepare the powders. The crystal structures of these powders were investigated using X-ray diffraction (XRD; Rigaku Co., Tokyo, Japan, RINT2500VHF/PC) with monochromatic $\mathrm{Cu} \mathrm{K} \alpha$ radiation $\left(50 \mathrm{kV}, 300 \mathrm{~mA}\right.$ ) in a step-scan mode over the $2 \theta$ range $5^{\circ}-60^{\circ}$ (step size 
$0.02^{\circ}$ and counting time $1.0 \mathrm{~s}$ ).

\section{Experimental Results}

Figure 2 shows the relationship between the micro Vickers hardness and sintering temperature in sintered TMA bodies are increase in $\mathrm{HV}$ with temperature above $1473 \mathrm{~K}$. However, this effect is degraded by cracking and cave-in of the impression above $1773 \mathrm{~K}$ in the vacuum-sintered bodies, or over $1673 \mathrm{~K}$ in the case of atmosphere-sintered bodies. Thus, a maximum HV $=400$ was obtained with vacuum sintering at a temperature of 1573 - $1673 \mathrm{~K}$, whereas atmospheric sintering at $1573 \mathrm{~K}$ only achieved a HV $=200$. For comparison the typical range of $\mathrm{HV}$ values for a human tooth are also shown, the precise value varying depending on age and sex. The location within the tooth also creates significant variation, with the having a $\mathrm{HV} \leq 150$, while the enamel is typically between 150 and 500 [15]. Given that bone is generally considered to be softer than teeth, these results suggest that the vacuum-sintering of TMA at 1473 - $1673 \mathrm{~K}$ produces sufficient hardness for use with both human teeth and bones.

The relationship between bending strength $\sigma_{b}$ and sintering temperature is shown in Figure 3, in which the

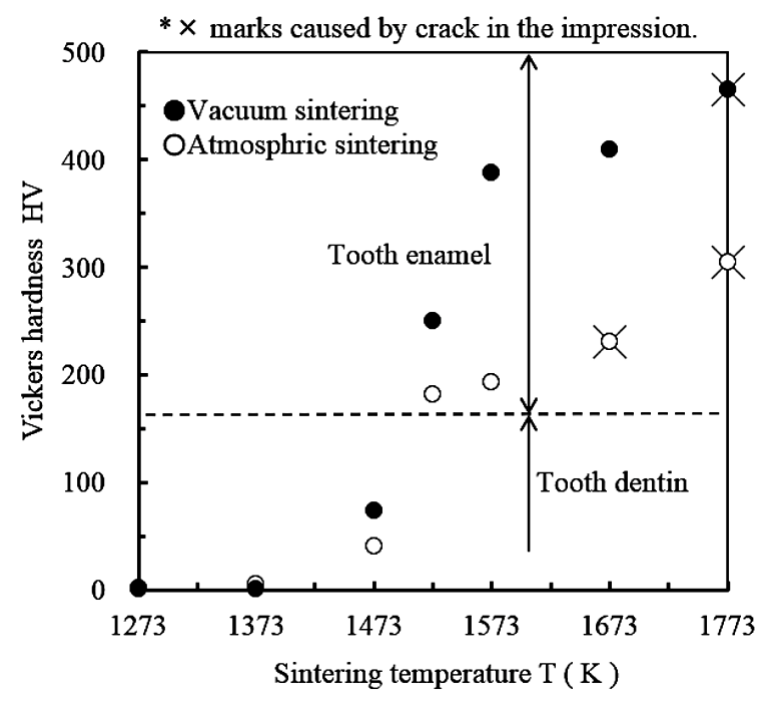

Figure 2. Relationship between micro Vickers hardness and sintering temperature in sintered TMA bodies.

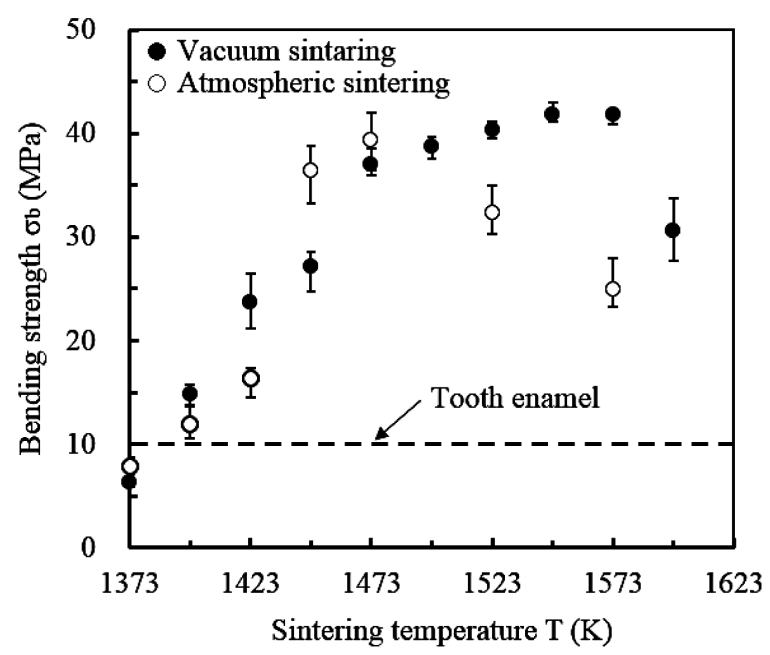

Figure 3. Relationship between bending strength and sintering temperature in sintered TMA bodies. 
error bars represent a variation between samples of that was not seen in the case of hardness. Nevertheless, it is clear from this that the bending strength of vacuum-sintered TMA bodies is increased with a sintering temperature of $1373 \mathrm{~K}$, but peaks at a value of $43 \mathrm{MPa}$ around $1573 \mathrm{~K}$. In contrast, the maximum bending strength achieved with sintering under atmosphere was $39 \mathrm{MPa}$ at around $1473 \mathrm{~K}$. The variation between samples also differed, with the $\pm 1 \%$ of the vacuum-sintered samples being notably more consistent than the $\pm 3 \%$ variation seen with sintering in atmosphere. If we consider that the bending strength of tooth enamel is about $10 \mathrm{MPa}$ [11], then it would seem that the TMA bodies vacuum-sintered at $1573 \mathrm{~K}$ would as a substitute for this natural material.

As shown in Figure 4, the compressive strength of the sintered TMA bodies increased at a sintering temperature of $1273 \mathrm{~K}$. In the case of vacuum-sintering, a maximum of $270 \mathrm{MPa}$ was reached at 1473 - $1573 \mathrm{~K}$, but with sintering in atmosphere this value was some 20 MPa lower. Thus for any given sintering temperature, the presence of oxygen has very little effect on compressive strength. More importantly, this strength is comparable to that of dentine and greater than that of bone [16], but does fall well short of the $400 \mathrm{MPa}$ of tooth enamel [17].

The SEM images of the fracture surfaces created by compression testing reveal that sintering is incomplete at a temperature of $1373 \mathrm{~K}$ (Figure 5(a)), but at $1573 \mathrm{~K}$ (Figure 5(b)) scaffolds of about $5 \mu \mathrm{m}$ in length are uniformly created throughout the sintered TMA body. In addition, the fracture surface of vacuum-sintered bodies is notably smoother than is seen in comparable bodies sintered in atmosphere.

\section{Discussion}

As there are as yet no standard diffraction patterns for TMA, the individual crystalline phases present in the sintered TMA bodies were determined by X-ray diffraction and are presented in Table 2 [10]. TMA is represented by the chemical formula $\left[\mathrm{Ca}_{10}\left(\mathrm{PO}_{4}\right)_{6}\right] \mathrm{TiO}_{3} \times n \mathrm{H}_{2} \mathrm{O}$, where $n$ is an integer from 0 to 3 [14]. The chemical formula of HAp is $\left[\mathrm{Ca}_{10}\left(\mathrm{PO}_{4}\right)_{6}\right](\mathrm{OH})_{2}$. TMA is formed by chemically connectinga Ti oxide molecule with the reactive $\left[\mathrm{Ca}_{10}\left(\mathrm{PO}_{4}\right)_{6}\right]$ group of HAp. The Ti content of TMA is approximately $4 \%$. There are no standard diffraction patterns obtained for TMA, so the crystalline compositions of the TMA sintered bodies were obtained using XRD. This revealed that the TMA powder is in fact a blend of two crystalline materials: HAp [hydroxyapatite- $\mathrm{Ca}_{5}\left(\mathrm{PO}_{4}\right)_{3}(\mathrm{OH})$ ] and anatase-TiO 2 . However, when sintered at $1073 \mathrm{~K}, \beta$-TCP [whitlockite-Ca $\left(\mathrm{PO}_{4}\right)_{2}$ ] and Perovskite-CaTiO${ }_{3}$ [18] [19] phases are produced by recrystallization. At $1273 \mathrm{~K}$ the initial HAp phase is no longer present, resulting in a structure of $\beta$-TCP and $\alpha$-TCP $\left[\mathrm{Ca}_{3}\left(\mathrm{PO}_{4}\right)_{2}\right]$ with anatase- $\mathrm{TiO}_{2}$. A further increase in temper ature to 1573 - $1773 \mathrm{~K}$ sees the elimination of both of the initial phases, leaving an entirely new crystalline structure of $\beta$-TCP, $\alpha$-TCP, and Perovskite- $\mathrm{CaTiO}_{3}$. This latter phase is produced as a result of the Ti oxide molecules in TMA forming chemical bonds with the reactive $\left[\mathrm{Ca}_{10}\left(\mathrm{PO}_{4}\right)_{6}\right]$ group of HAp, and represents a very hard and stable material, whereas $\beta$-TCP and $\alpha$-TCP are of course naturally present in bone.

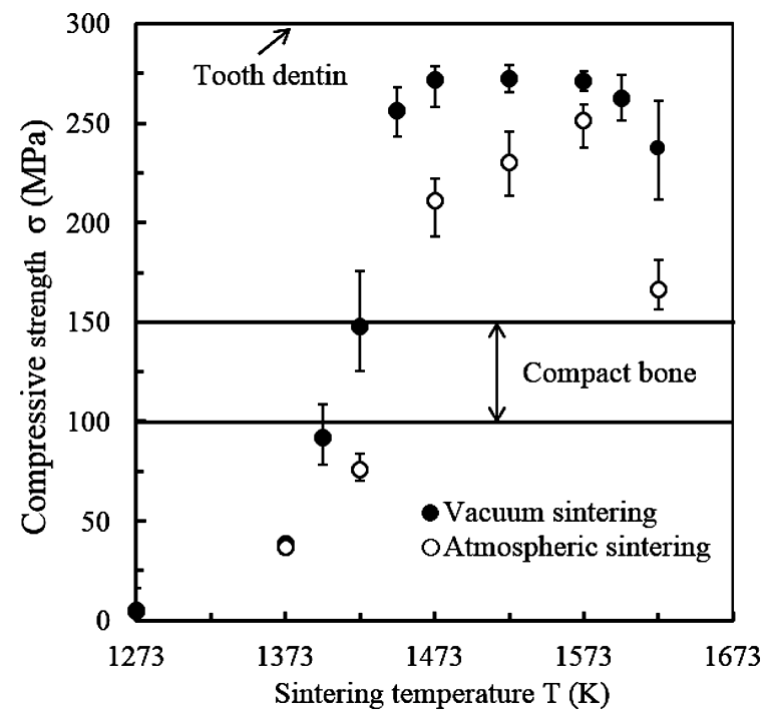

Figure 4. Relationship between compressive strength and sintering temperature in sintered TMA bodies. 


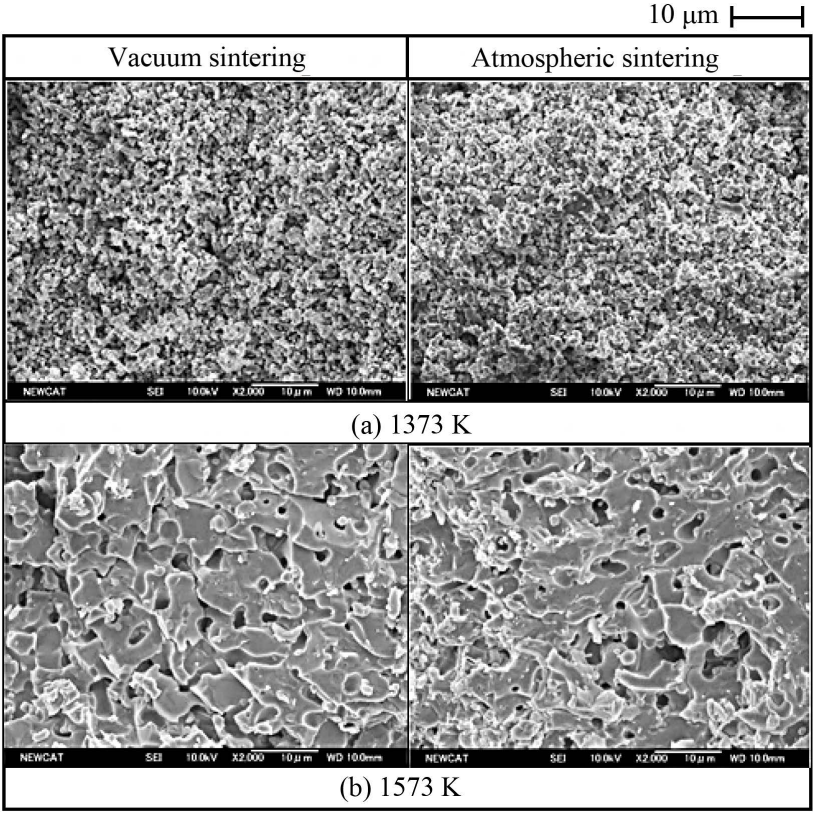

Figure 5. SEM images of the fractures produced by the compression testing of sintered TMA bodies.

Table 2. Crystal phase morphology of sintered TMA bodies.

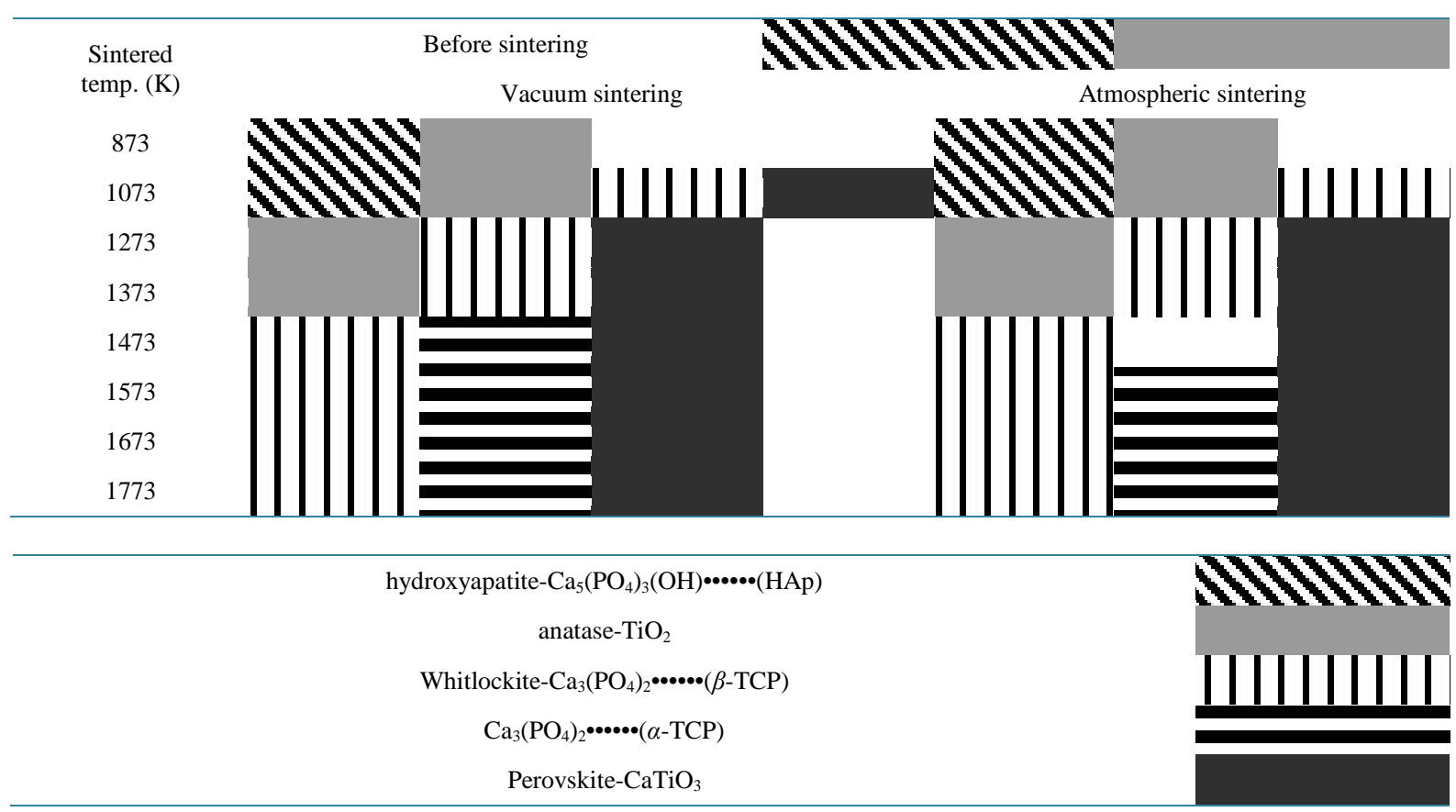

Interestingly, although the crystalline phases formed in the atmosphere-sintered bodies appeared similar to those in the vacuum-sintered bodies, micrographs taken under polarized light revealed differences in the distribution of Perovskite crystals (shown in white in Figure 6 [10]). Specifically, these crystals are transformed under vacuum sintering into cylindrical fibers approximately $1 \mu \mathrm{m}$ in diameter and $8 \mu \mathrm{m}$ in length; and as these grew uniformly in all directions, are observed as grains of various lengths on the surface. In contrast, the Perovskite crystals in the atmosphere-sintered body were condensed and heterogeneously distributed in the outer part of the sintered body, yet there were no significant change in the central part of the sintered body. This is 
most likely the result of bonding between $\mathrm{Ti}$ and $\mathrm{O}_{2}$ in the outer part of the sintered body, thus making this region more difficult to cut than the center.

The maximum average value of hardness, bending strength and compressive strength in TMA sintered bodies are shown in Table 3. In result, the maximum average value of the three factors are given in the vacuum-sintering at $1573 \mathrm{~K}$. Moreover, TMA vacuum-sintered body at $1573 \mathrm{~K}$ by simply cutting with a 3D-modeling machine or a lathe (Figure 1). Human tooth and human bone have different parameters about hardness, bending strength and compressive strength. However, TMA vacuum-sintered body at $1573 \mathrm{~K}$ is considered suitable for use as the biomaterials.

\section{Conclusions}

Through this investigation into the influence of sintering temperature on the physical strength of titanium medical apatite (TMA), the following conclusions have been drawn:

1) The vacuum-sintering of TMA powder at $1573 \mathrm{~K}$ can achieve a Vickers hardness of 400 , a bending strength of $43 \mathrm{MPa}$ and a compressive strength of $270 \mathrm{MPa}$. As these values are comparable to human teeth and compact human bone, this material is considered suitable for use as artificial bone. However, it is important to exclude oxygen during the sintering process, as this can reduce both the hardness and strength of the sintered body.

2) Sintering TMA powder at 1473 - $1773 \mathrm{~K}$ creates new crystalline phases of $\beta$-TCP, $\alpha$-TCP and Perovskite-CaTiO ${ }_{3}$. With vacuum-sintering, the Perovskite is present as a uniform distribution of evenly sized fibers in all directions, but the presence of oxygen during sintering results in these fibers being uneven in size and concentrated near the surface of the sintered body.

3) Sintered TMA bodies can be easily machined into various forms, which combined with their aforementioned physical properties, makes them a promising biomaterial for use as an artificial bone material in the regeneration of bone parts and the fabrication of bone junction reinforcement structures for dental and orthopedic surgery.

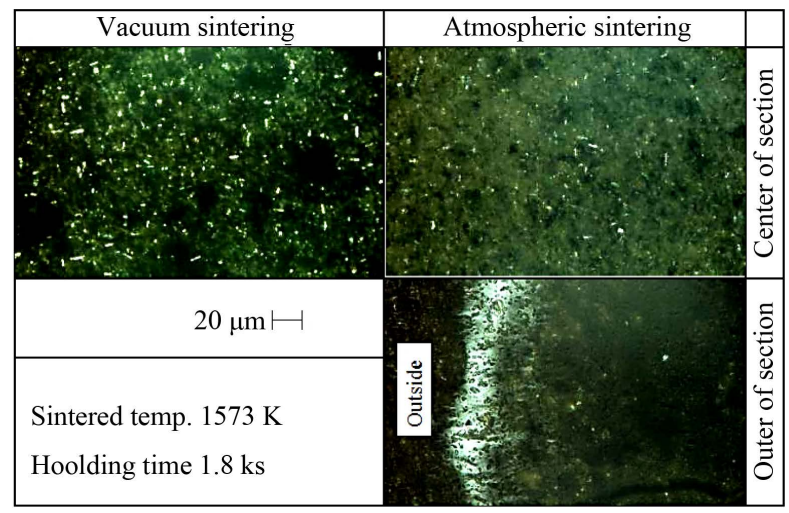

Figure 6. Polarized light micrographs of Perovskite crystals in sintered TMA bodies.

Table 3. The maximum value of hardness, bending strength and compressive strength in TMA sintered bodies.

\begin{tabular}{ccccccc}
\hline $\begin{array}{c}\text { Sintered } \\
\text { temp. } \\
(\mathrm{K})\end{array}$ & Hardness & $\begin{array}{c}\text { Vacuum sintering } \\
\text { Bending }\end{array}$ & $\begin{array}{c}\text { Compression } \\
(\mathrm{MPa})\end{array}$ & Hardness & $\begin{array}{c}\text { Bending } \\
(\mathrm{MPa})\end{array}$ & $\begin{array}{c}\text { Atmospheric sintering } \\
\text { Compression } \\
(\mathrm{MPa})\end{array}$ \\
\cline { 2 - 7 } 1473 & 73 & 35 & 270 & 41 & 39 & 210 \\
1573 & 400 & 43 & 270 & 200 & 25 & - \\
1598 & - & 31 & 263 & - & - & - \\
1623 & - & 31 & 238 & - & - \\
\hline
\end{tabular}




\section{Acknowledgements}

The author greatly appreciates and acknowledges the advice and support provided by the former President of Immuno-Science Co., Ltd., Yuriko Morisaki, and the same company’s current Vice-President, Tatsushi Fujita.

\section{References}

[1] Tsutsumi, Y., Takano, Y., Doi, H., Noda, K. and Hanawa, T. (2007) Corrosion Behavior of Zirconium Based Alloys inSimulated Body Fluids. Materials Science Forum, 561-565, Switzerland (Trans Tech Publications), 1489-1492.

[2] Matsumoto, H., Kurosu, S., Lee, B., et al. (2010) Deformation Mode in Biomedical Co-27\% Cr-5\% Mo Alloy Consisting of a Single Hexagonal Close-Packed Structure. Scripta Materialia, 63, 1092-1095. http://dx.doi.org/10.1016/j.scriptamat.2010.08.006

[3] Alfirano, Mineta, S., et al. (2011) Precipitates in As-Cast and Heat-Treated ASTM F75 Co-Cr-Mo-C Alloys Containing Si and/or Mn. Metallurgical and Materials Transactions A, 42A, 1941-1949.

[4] Niinomi, M., Akahori, T. and Nakai, M. (2008) In Situ X-Ray Analysis of Mechanism of Nonlinear Super Elastic Behavior of Ti-Nb-Ta-Zr System Beta-Type Titanium Ally for Biomedical Applications. Materials Science and Engineering, C28, 406-413. http://dx.doi.org/10.1016/j.msec.2007.04.028

[5] Sugiyama, N., et al. (2009) Bioactive Titanate Nanomesh Layer on the Ti-Based Bulk Metallic Glass by Hydrothermal-Electrochemical Technique. Acta Biomaterialia, 5, 1367-1373. http://dx.doi.org/10.1016/j.actbio.2008.10.014

[6] Niki, Y. (2012) Metal Hypersensitivity in Field of Orthopaedic Surgery. Japanese Society for Biomaterials, 30, 113116.

[7] Ohtsu, N., Sembori, S., et al. (2011) Fabricatoin of Composite Coating Comprising Bioactive Calcium and Sodium Titanates on Titanium Using Calcium Hydroxide Slurry Containing Ions. Surface \& Coatings Technology, 205, 37853790. http://dx.doi.org/10.1016/j.surfcoat.2011.01.035

[8] Hanawa, T. (2010) Biofunctionalization of Titanium for Dental Implant. Science Direct, 46, 93-101.

[9] Saito, M. (2002) Bone Graft Substitutes in Orthopaedic Surgery. Japanese Society for Biomaterials, 20, 329-336.

[10] Tamura, K., Fujita, T. and Morisaki, Y. (2013) Vacuum-Sintered Body of a Novel Apatite for Artificial Bone. Central European Journal of Engineering, 3, 700-706. http://dx.doi.org/10.2478/s13531-013-0127-4

[11] Aoki, H. (1999) Marvelous Biomaterial Apatite. Ishiyaku Publishers, Inc., Tokyo.

[12] Hayashi, M., Tamura, K., et al. (2010) Influence of Sintered Body of Titanium Medical Apatite (TMA) on Osteoblastic Activity. Nihon University Dental Journal, 84, 93-96.

[13] Hayashi, M., Tamura, K., et al. (2011) The Biocompatibility of Novel Apatite Chemically Bonded with Titanium Dioxide as Potential Bone Substitute. World Congress for Oral Implantology (WCOI) Year Book 2010, 35-39.

[14] Fujita, T., Tamura, K. and Morisaki, Y. (2005) Sintered Body of Titanium Compound. Publication No. for an International Patent, W02005-058754.

[15] Mezawa, S., Kawano, T., Yoshida, K., Nozaki, H., Saito, T., Tamura, K. and Onozawa, M. (1999) Evaluation of Human Tooth Structure with the Ultrasonic Imaging Technique. Journal of Oral Science, 41, 191-197. http://dx.doi.org/10.2334/josnusd.41.191

[16] Currey, J.D. (1970) The Mechanical Properties of Bone. Clinical Orthopaedics and Related Research, 73, $210-231$. http://dx.doi.org/10.1097/00003086-197011000-00023

[17] Craig, R.G., Peyton, F.A. and Johnson, D.W. (1961) Compressive Properties of Enamel, Dental Cements, and Gold. J. D. Res. September-October, 40, 936-945.

[18] Dana, J.D. and Dana, E.S. (1997) Dana’s New Mineralogy. John Wiley \& Sons, Inc., New York.

[19] Housecroft, C.E. and Sharpe, A.G. (2008) Inorganic Chemistry. 3rd Edition, Pearson Education Limited. 
Scientific Research Publishing (SCIRP) is one of the largest Open Access journal publishers. It is currently publishing more than 200 open access, online, peer-reviewed journals covering a wide range of academic disciplines. SCIRP serves the worldwide academic communities and contributes to the progress and application of science with its publication.

Other selected journals from SCIRP are listed as below. Submit your manuscript to us via either submit@scirp.org or Online Submission Portal.
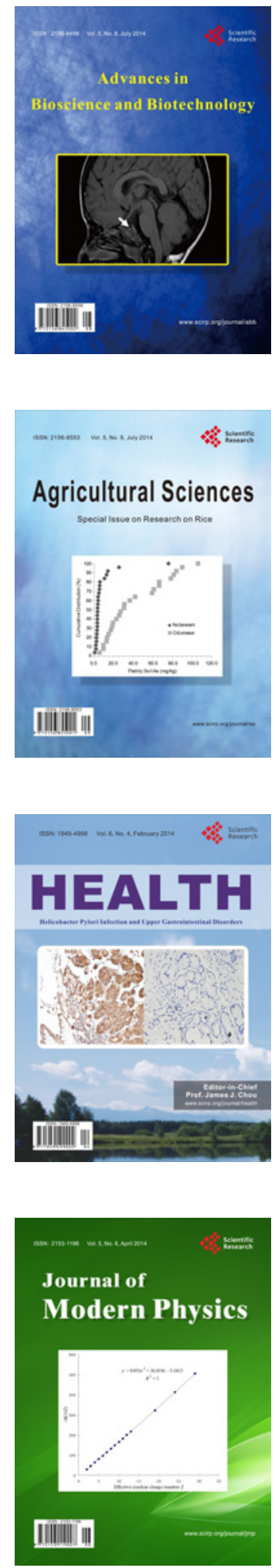
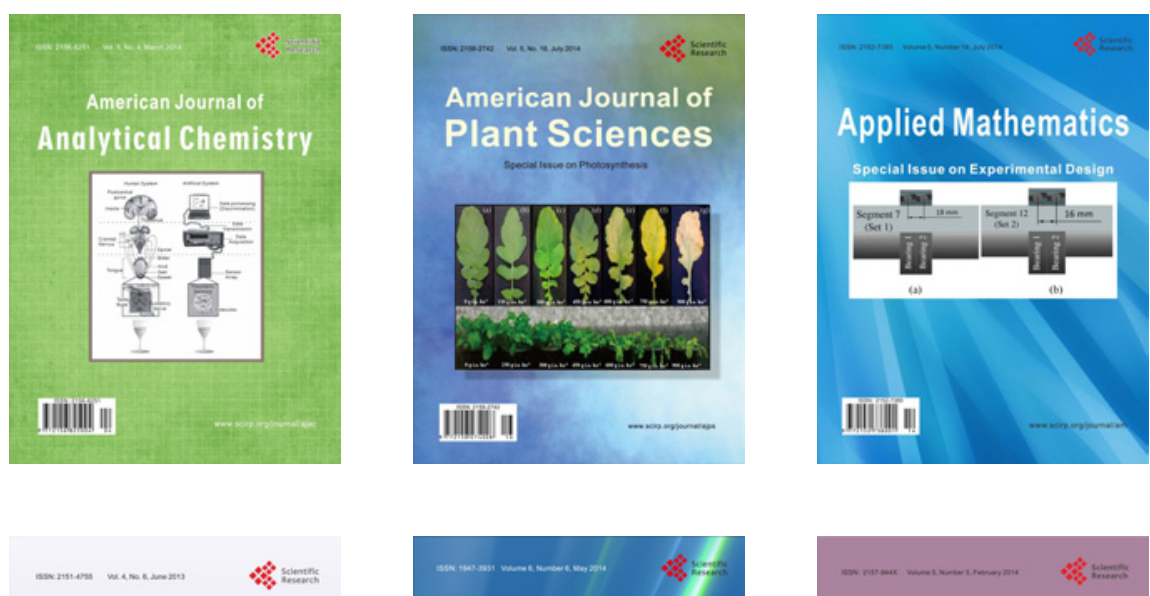

Creative Education
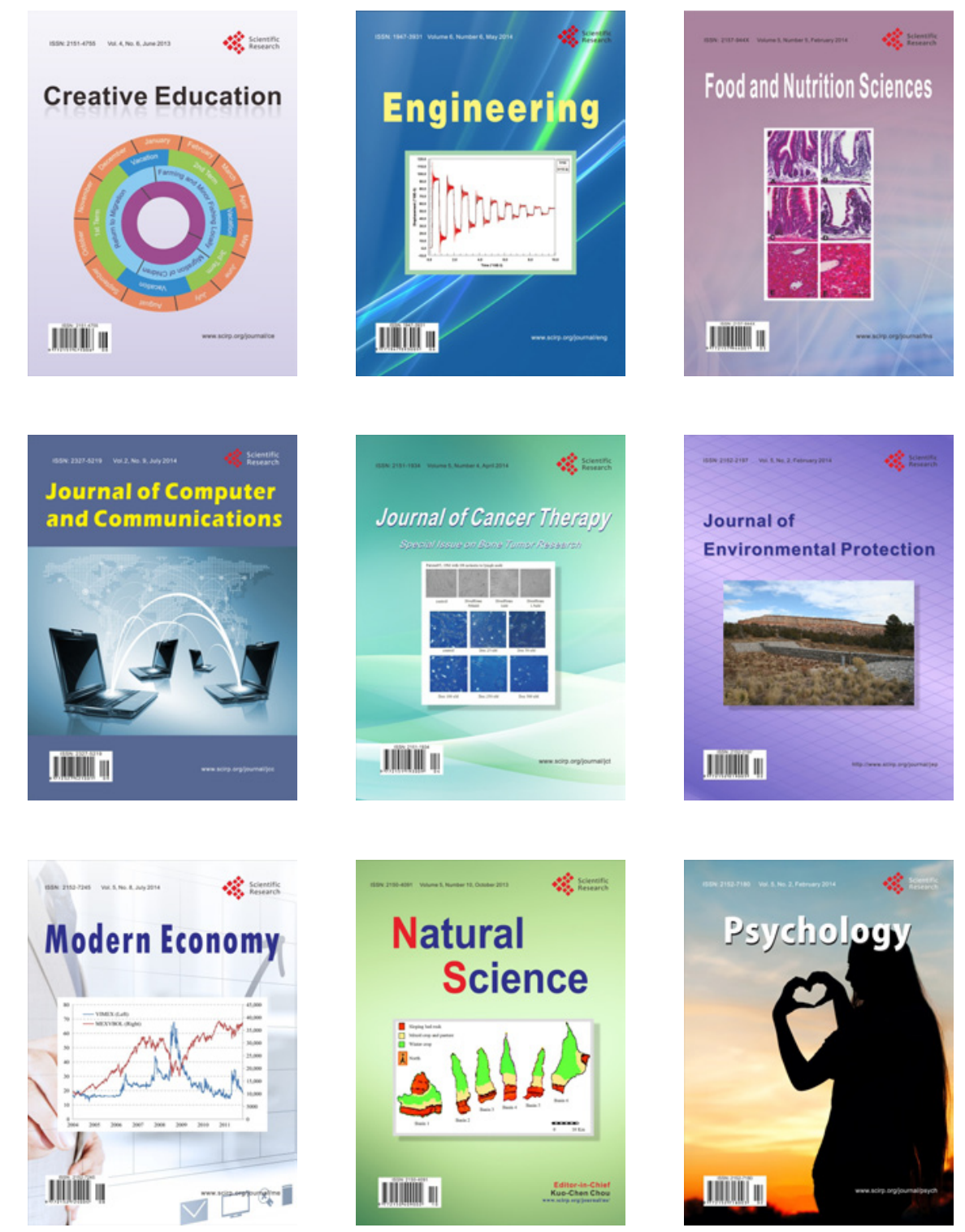